\title{
Effect of pregnancy induced hypertension on pregnancy outcome: a hospital based cross sectional study at a tertiary care hospital
}

\author{
K. Hima Bindu*, E. Rama Devi
}

Department of Obstetrics and Gynecology, Chalmeda Anand Rao Institute of Medical Sciences, Bommakal, Karimnagar, Telangana, India,

Received: 11 February 2018

Accepted: 09 March 2018

\section{*Correspondence:}

Dr. K. Hima Bindu,

E-mail: himabindudr1979@gmail.com

Copyright: (c) the author(s), publisher and licensee Medip Academy. This is an open-access article distributed under the terms of the Creative Commons Attribution Non-Commercial License, which permits unrestricted non-commercial use, distribution, and reproduction in any medium, provided the original work is properly cited.

\begin{abstract}
Background: I Pregnancy induced hypertension causes intra uterine growth retardation, pre-mature delivery, intra uterine death of fetus, abruption placentae. It also causes increased morbidity and mortality among women. The objective of the present study is to observe the effect of pregnancy induced hypertension on pregnancy outcome.

Methods: A hospital based cross sectional study was carried out to study the effect of pregnancy induced hypertension on pregnancy outcome for a period of two years from April 2004 to March 2006 at Gandhi Medical College, Hyderabad.

Results: The mean maternal age in group I was 22.9 years comparable to group II. The incidence of PIH was $10.7 \%$ among primipara compared to $9.1 \%$ among multi parous women. Mean gestational age at entry to the present study was comparable among both the groups. Mean gestational age at delivery was higher in normotensive women compared to women with PIH. The incidence of low birth weight was $70 \%$ among PIH group compared to only $16.7 \%$ in normotensive group and this difference was found to be statistically significant. The incidence of intrauterine growth retardation (IUGR) was $70 \%$ among PIH group compared to only $16.7 \%$ in normotensive group and this difference was found to be statistically significant. The incidence of pre-term delivery was $70 \%$ among PIH group compared to only $16.7 \%$ in normotensive group and this difference was found to be statistically significant.

Conclusions: T Pregnancy induced hypertension was positively associated with adverse outcome. Early diagnosis and proper management can help to overcome and tackle most of the adverse outcomes.
\end{abstract}

Keywords: Management, Outcome, Pre-term delivery

\section{INTRODUCTION}

Globally around $10 \%$ of the pregnant women develop pregnancy induced hypertension. Pregnancy induced hypertension is associated with increased morbidity and mortality among pregnant women. Systolic blood pressure more than $140 \mathrm{mmHg}$ and diastolic blood pressure more than $90 \mathrm{mmHg}$ is termed as pregnancy induced hypertension if it is taken two times or if taken only once and showing Systolic blood pressure more than $160 \mathrm{mmHg}$ and diastolic blood pressure more than 110 $\mathrm{mmHg}$ is termed as pregnancy induced hypertension. This must be in a woman who was previously having normal blood pressure. ${ }^{1}$ It has been estimated that five to seven percent of pregnancies are affected by preeclampsia. When a woman with pre-eclampsia develops convulsions, it is called as eclampsia when the physician has ruled out other causes for convulsions. ${ }^{2}$ Pregnancy 
induced hypertension causes intra uterine growth retardation, pre-mature delivery, intra uterine death of fetus, abruption placentae. It also causes increased morbidity and mortality among women. ${ }^{3}$

Significant association has been found between peri natal mortality and pregnancy induced hypertension. Some authors found that there was no association between peri natal mortality and pregnancy induced hypertension. But it was definitely associated with intra uterine growth retardation, pre-mature delivery, intra uterine death of fetus, abruption placentae. ${ }^{4}$ It has been observed by authors that women with pregnancy induced hypertension were likely to give birth to low birth weight babies than women without pregnancy induced hypertension. ${ }^{5}$ Hypertensive disorder of pregnancy is an important public health problem. This is due to its dreaded complications. This is also due to increased mortality and morbidity associated with it. Risk of maternal death is increased in women with pregnancy induced hypertension. Perinatal death is a more dreaded complication of pregnancy induced hypertension. It has been estimated that the incidence of maternal death is $1 \%$ in women with pregnancy induced hypertension and the risk of perinatal death is $13 \%$ in women with pregnancy induced hypertension. It has been estimated that the incidence of maternal death is $5 \%$ in women with eclampsia and the risk of perinatal death is $13 \%$ in women with eclampsia. ${ }^{6}$

Hypertensive disorder of pregnancy is associated with huge perinatal deaths. This is due to insufficiency of placenta, abruption placentae, and other associated complications. They are severe in nature. ${ }^{7}$ Hence present study was carried out to study the effect of pregnancy induced hypertension on pregnancy outcome.

\section{METHODS}

A hospital based cross sectional study was carried out to study the effect of pregnancy induced hypertension on pregnancy outcome for a period of two years from April 2004 to March 2006 at Gandhi Medical College, Hyderabad.Blood pressure and mean arterial blood pressure was measured and recorded as per standard guidelines for all included women in the present study.
In a previously normotensive woman, Systolic blood pressure of more than $140 \mathrm{mmHg}$ and a diastolic blood pressure of more than $90 \mathrm{mmHg}$ or the mean arterial blood pressure of more than $110 \mathrm{mmHg}$ or rise of more than $20 \mathrm{mmHg}$ after 20 weeks of gestation was taken as pregnancy induced hypertension.

Blood pressure was recorded in the sitting position in right upper limb with mercury sphygmomanometer Korotkoff phase $\mathrm{V}$ as indicative of diastolic blood pressure. Same procedure was followed for all women.

The blood pressure apparatus was standardized each time the blood pressure was measured. Mean arterial blood pressure was calculated by using the formula of adding the systolic blood pressure to twice that of diastolic blood pressure and then dividing this sum by three.

Mean arterial blood pressure of 90-109 mmHg was taken as mild pregnancy induced hypertension. Mean arterial blood pressure of more than $110 \mathrm{mmHg}$ was taken as severe pregnancy induced hypertension. Birth weight of less than $2500 \mathrm{gm}$ was taken as low birth weight. If the birth weight was less than 10th percentile then it was taken as intra uterine growth retardation. If the delivery occurred before 37 completed weeks of gestation, then it was taken as pre-term delivery. Data like age, systolic blood pressure, diastolic blood pressure, last menstrual period date, social class, expected date of delivery, history of consanguinity, duration of married life, history of contraception, last child birth details, detailed obstetric history, detailed menstrual history, family history, personal history are taken and recorded in the pre designed, pre tested, semi structured study questionnaire designed for the present study.

The data was entered in the Microsoft excel worksheet and analyzed using proportions, chi square test.

\section{RESULTS}

The mean maternal age in group I was 22.9 years comparable to group II. The incidence of PIH was $10.7 \%$ among primipara compared to $9.1 \%$ among multi parous women.

Table 1: Maternal characteristics of study subjects in both the groups.

\begin{tabular}{|lllll|}
\hline Variable & Group I & Group II & Total & P value \\
\hline Mean maternal age (years) & 22.9 & 25.2 & 23.21 \\
\hline Primipara & $55.5 \%$ & $60 \%$ & $56 \%$ \\
\hline Multi para & $44.5 \%$ & $40 \%$ & $44 \%$ & \\
\hline Mean gestational age at entry (in weeks) & 16 & 15.8 & 15.8 \\
\hline Mean gestational age at delivery (in weeks) & 38.7 & 35.2 & 38.35 & $<0.01$ \\
\hline Mean SBP (mmHg) & 120.1 & 170 & 125.1 & $<0.01$ \\
\hline Mean DBP (mmHg) & 75.7 & 110 & 79.2 & $<0.01$ \\
\hline Mean MAP (mmHg) & 90.5 & 129.6 & 95.2 & \\
\hline
\end{tabular}


Mean gestational age at entry to the present study was comparable among both the groups. Mean gestational age at delivery was higher in normotensive women compared to women with PIH.

Table 2: Effect of PIH on pregnancy outcome.

\begin{tabular}{llll}
$\begin{array}{l}\text { Pregnancy } \\
\text { outcome }\end{array}$ & $\begin{array}{l}\text { Group I } \\
\text { (normotensive) } \%\end{array}$ & $\begin{array}{l}\text { Group II } \\
(\text { PIH) \% }\end{array}$ & P value \\
$\begin{array}{l}\text { Low birth } \\
\text { weight }\end{array}$ & 16.7 & 70 & $<0.001$ \\
\hline IUGR & 11.1 & 40 & $<0.001$ \\
\hline $\begin{array}{l}\text { Pre-term } \\
\text { delivery }\end{array}$ & 11.1 & 60 & $<0.001$ \\
\hline
\end{tabular}

Table 2 shows effect of PIH on pregnancy outcome. The incidence of low birth weight was $70 \%$ among PIH group compared to only $16.7 \%$ in normotensive group and this difference was found to be statistically significant. The incidence of intra-uterine growth retardation (IUGR) was $70 \%$ among PIH group compared to only $16.7 \%$ in normotensive group and this difference was found to be statistically significant. The incidence of pre-term delivery was $70 \%$ among PIH group compared to only $16.7 \%$ in normotensive group and this difference was found to be statistically significant.

\section{DISCUSSION}

The mean maternal age in group I was 22.9 years comparable to group II. The incidence of PIH was $10.7 \%$ among primipara compared to $9.1 \%$ among multi parous women. Mean gestational age at entry to the present study was comparable among both the groups. Mean gestational age at delivery was higher in normotensive women compared to women with PIH. The incidence of low birth weight was $70 \%$ among PIH group compared to only $16.7 \%$ in normotensive group and this difference was found to be statistically significant. The incidence of intra-uterine growth retardation (IUGR) was $70 \%$ among $\mathrm{PIH}$ group compared to only $16.7 \%$ in normotensive group and this difference was found to be statistically significant. The incidence of pre-term delivery was $70 \%$ among PIH group compared to only $16.7 \%$ in normotensive group and this difference was found to be statistically significant.

Adu-Bonsaffoh $\mathrm{K}$ et al found that hypertensive disorder of pregnancy was associated with many complications. ${ }^{8}$ They noted that $24.7 \%$ of the new born children were to be admitted to NICU due to complications arising out of delivery to the women with hypertensive disorders of pregnancy. $15.2 \%$ of the cases among neonates developed asphyxia. Among them $3.8 \%$ needed to give support on ventilator. $21.7 \%$ of the cases were pre-term. The incidence of still birth was $6.8 \%$. The incidence of early neonatal death was $3.8 \%$. The incidence of IUGR was $6.1 \%$. The incidence of low birth weight was $6.8 \%$. All these complications were found more common among women with hypertensive disorder of pregnancy.
Browne JL et al in their study found that incidence of pregnancy induced hypertension was $7.5 \% .^{9}$ Hypertension of chronic nature was found in $2 \%$ of women. Surprisingly authors noted that women with pregnancy induced hypertension did not develop any complications. This finding is not similar to the finding of the present study. But they observed that the mean gestational age at delivery was lower in women with chronic hypertension compared to women with normal blood pressure. Women with chronic hypertension were found to have some 4.63 times more risk of having preterm delivery than women with normal blood pressure. More proportion of women with chronic hypertension was found to have likelihood of caesarean section delivery compared to women with normal blood pressure. Women with chronic hypertension were found to have some 7.95 times more risk of having low birth weight babies than women with normal blood pressure. Women with chronic hypertension were found to have some 18.41 times more risk of having risk of neonatal death than women with normal blood pressure.

Adu-Bonsaffoh $\mathrm{K}$ et al analyzed the reasons for the maternal deaths and found that out of 10 deaths, ${ }^{10}$ three were due to hypertensive disorder of pregnancy. The incidence of caesarean section was $45.7 \%$. The incidence of abruption placentae was $3 \%$. The incidence of pulmonary edema was $0.8 \%$. The incidence of acute renal failure was $0.5 \%$. The incidence of disseminated intravascular coagulation was $1.9 \%$ and the incidence of eclampsia was $15.8 \%$.

Terefe $\mathrm{W}$ et al noted that the incidence of hypertensive disorder of pregnancy was $3.9 \% .{ }^{11}$ The authors noted that over the years from 2011 to 2014, the incidence increased from $1.8 \%$ to $5.7 \%$. hypertensive disorder of pregnancy was found to be associated with adverse outcomes like pre-term delivery in $35.4 \%$ of the cases, death of fetus in $30.8 \%$ of the cases, low birth weight in $39.4 \%$ of the cases, low score of APGAR in $38.4 \%$ of the cases, intra uterine growth retardation in $8.5 \%$ of the cases. Death occurred in $2.5 \%$ of the cases who had hypertensive disorder of pregnancy.

Muti $\mathrm{M}$ et al found that the prevalence of pregnancy induced hypertension was $19.4 \%$ in their study. ${ }^{12}$ Risk of giving birth to a low birth weight baby was three times more in women with pregnancy induced hypertension compared to women with normal blood pressure. Risk of still birth was 4.34 times more in women with pregnancy induced hypertension compared to women with normal blood pressure. Risk of having a baby who had very low APGAR score was four times more in women with pregnancy induced hypertension compared to women with normal blood pressure.

Heard AR et al divided women into three groups like women with already having hypertension, ${ }^{13}$ women having pregnancy induced hypertension and women with super imposed pre-eclampsia and compared them with 
one group of women with normal blood pressure. They found that all groups of women with hypertension had increased incidence of induced labour as well as caesarean section but still the women in the group of superimposed pre-eclampsia had highest incidence. All groups of women with hypertension had increased incidence of low birth weight, and other complications. Women with superimposed pre-eclampsia had most number of complications followed by women with pregnancy induced hypertension and this was followed by women with already having hypertension.

Adu-Bonsaffoh $\mathrm{K}$ et al in their study of a large scale found that $31.7 \%$ of the mothers died due to hypertensive disorder of pregnancy. ${ }^{14} 7.6 \%$ was the incidence of hypertensive disorder of pregnancy. Hypertensive disorder of pregnancy was found to be associated with secondary hemorrhage in $26.6 \%$ of the cases, puerperal sepsis in $3.5 \%$ of the cases.

\section{CONCLUSION}

Pregnancy induced hypertension was positively associated with adverse outcome. Early diagnosis and proper management can help to overcome and tackle most of the adverse outcomes. We can definitely reduce the incidence of adverse outcomes among women with pregnancy induced hypertension.

Funding: No funding sources

Conflict of interest: None declared

Ethical approval: The study was approved by the Institutional Ethics Committee

\section{REFERENCES}

1. Baha SM. Diagnosis and Management of Gestational Hypertension and Preeclampsia. Obstet Gynecol. 2003;102(1):181-92

2. Srinivas SK, Edlow AG, Neff PM, Sammel MD, Andrela CM et al. Rethinking IUGR in preeclampsia: dependent or independent of maternal hypertension? J Perinatol 2009;29(10):680-4.

3. Anand S, Anand K, Perinatal Outcome in Growth Retarted Babies Born to Normotensive and Hypertensive Mothers: A Prospective Study. People's J Sci Res. 2012;5(1):24-8

4. Hauth JC, Ewell MG, Levine RJ, Esterlitz JR, Sibai B, Curet LB et al. Pregnancy Outcomes in Healthy Nullipara Who Developed Hypertension. Obstet Gynecol 2000;95(1):24-28.
5. Rahman LA, Hairi NN, Salleh N. Association between Pregnancy Induced Hypertension and Low Birth Weight; A Population Based Case-Control Study. Asia Pac J Public Health. 2008;20(2):152-8.

6. Duley L. The global impact of pre-eclampsia and eclampsia. Semin Perinatol. 2009;33(3):130-7

7. World Health Organization. Neonatal and perinatal mortality: country, regional and global estimates. 2006

8. Adu-Bonsaffoh K, Ntumy MY, Obed SA, Seffah JD. Perinatal outcomes of hypertensive disorders in pregnancy at a tertiary hospital in Ghana. BMC Pregnancy Childbirth 2017;17(1):388.

9. Browne JL, Vissers KM, Antwi E, Srofenyoh EK, Van der Linder EL, Agyepond IA et al. Perinatal outcomes after hypertensive disorders in pregnancy in a low resource setting. Trop Med Int Health. 2015;20(12):1778-86.

10. Adu-Bonsaffoh K, Obed SA, Seffah JD. Maternal outcomes of hypertensive disorders in pregnancy at Korle Bu Teaching Hospital, Ghana. Int J Gynecol Obstet. 2014;127(3):238-42.

11. Terefe W, Getachew Y, Hiruve A, Derbew M, Mariam DH, Mammo D et al. Patterns of hypertensive disorders of pregnancy and associated factors at debre berhan referral hospital, north shoa, amhara region. Ethiop Med J. 2015;2:57-65.

12. Muti M, Tshimanga M, Notion GT, Bangure D, Chonzi P. Prevalence of pregnancy induced hypertension and pregnancy outcomes among women seeking maternity services in Harare, Zimbabwe. BMC Cardiovasc Disord. 2015;15(1):111.

13. Heard AR, Dekker GA, Chan A, Jacobs DJ, Vreeburg SA, Priest KR. Hypertension during pregnancy in South Australia, part 1: pregnancy outcomes. Aust-NZ J Obstet Gynecol 2004 Oct;44(5):404-9.

14. Adu-Bonsaffoh K, Oppong SA, Binlinla G, Obed SA. Maternal deaths attributable to hypertensive disorders in a tertiary hospital in Ghana. Int $\mathbf{J}$ Gynecol Obstet. 2013;123(2):110-3.

Cite this article as: Bindu K. H, Devi E. H. Effect of pregnancy induced hypertension on pregnancy outcome: a hospital based cross sectional study at a tertiary care hospital. Int J Reprod Contracept Obstet Gynecol 2018;7:1984-7. 